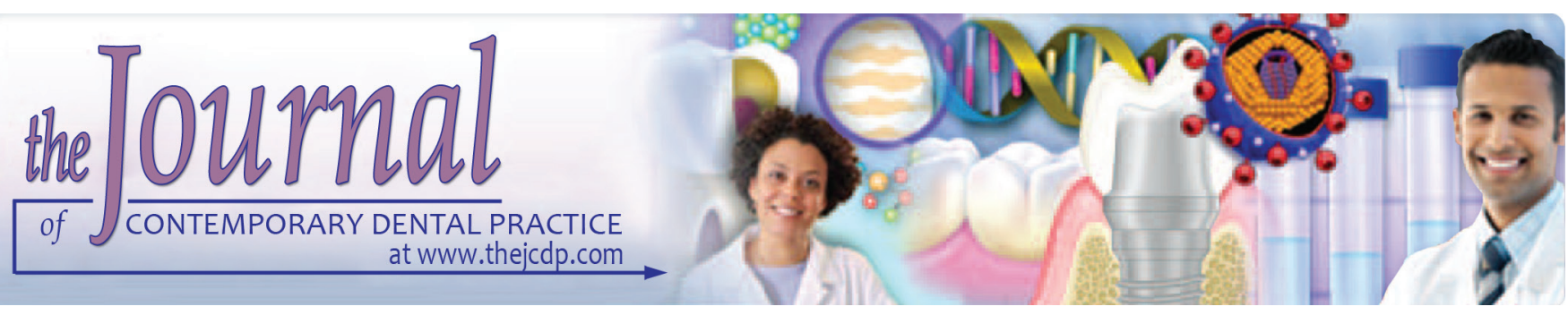

\title{
An In Vivo Study to Compare Location of Neutral Zone Recorded with Two Materials
}

\author{
${ }^{1}$ Saurabh Chaturvedi, ${ }^{2}$ Adel M Abdelmonem, ${ }^{3}$ Satheesh Haralur, ${ }^{4}$ Ghazala Suleman, ${ }^{5}$ Muhammad I Majeed, \\ ${ }^{6}$ Mohammed A Alfarsi
}

\section{ABSTRACT}

Aim: To establish a relationship between the crest of the alveolar ridge and neutral zone and to compare its location recorded by two different material.

Methods and materials: Thirty subjects were selected, and the location of the neutral zone was compared with the mandibular alveolar ridge crest. For each subject neutral zone was recorded by two different recording materials-Low fusing impression compound and tissue conditioner. After neutral zone recording, the relation between mandibular ridge crest and neutral zone location examined radiographically. The data so collected were checked for normality, descriptive statistics and the Mann-Whitney $U$ test was used.

Results: Position of neutral zone was found towards lingual in the posterior, labial side in anterior and almost near to the alveolar ridge crest in premolar region. The thermoplastic flow of the material effects the position of neutral zone but no significant difference was noted in the positions of neutral zone recorded by the two materials in relation to the alveolar ridge crest.

Conclusion: Location of the neutral zone is not affected by the material used in recording it.

Clinical significance: The location of the neutral zone varies from subject to subject and mainly depends upon their musculature and can be recorded accurately by using correct technique irrespective of the materials used.

Keywords: Low fusing impression compound, Neutral zone, Resorbed ridge, Tissue conditioners.

How to cite this article: Chaturvedi $S$, Abdelmonem AM, Haralur S, Suleman G, Majeed MI, Alfarsi MA. An In Vivo Study to Compare Location of Neutral Zone Recorded with Two Materials. J Contemp Dent Pract 2019;20(2):239-246.

${ }^{1-6}$ Department of Prosthetic Dentistry, College of Dentistry, King Khalid University, Abha, Kingdom of Saudi Arabia

Corresponding Author: Saurabh Chaturvedi, Department of Prosthetic Dentistry, College of Dentistry, King Khalid University, Abha, Kingdom of Saudi Arabia, e-mail: smc1@ live.in

\section{Source of support: Nil}

Conflict of interest: None

\section{INTRODUCTION}

The ultimate goal of prosthetic dentistry is to preserve the remaining tissues while replacing the lost one. The treatment would be considered successful if the prosthesis functions proficiently and in congruence with the muscles of the stomatognathic system and associated joints. ${ }^{1}$ The primary objective of complete denture prosthesis is esthetics, phonetics, and mastication. This can be accomplished only if the dentures have retention and stability. In this teeth position, form and contour of the flange play an important role along with other factors. If the flanges are not in harmony with the normal neuromuscular system or position of teeth in dentures are inappropriate,the success of the dentures will be ill effected. ${ }^{2}$ All oral functions- phonetics, swallowing, chewing, laughing involve the coordinated actions of the structures of oral cavity which are very complex and distinct in themselves. The harmonization of complete dentures with neuromuscular function can be accomplished by utilizing the neutral zone concept. ${ }^{3}$ It was Sir E. Wilfred Fish who proposed neutral zone (NZ) in complete denture in 1931. He stated that natural teeth capture "zone of equilibrium," resultant of varied forces propounding on it. ${ }^{4,5}$ Since then, many others have helped to improve and enhance both the theoretical basis and the clinical problems related to NZ. Russel stated it as "Reciprocal space." ${ }^{\prime 6}$ Robert mentioned it the "Potential space," ${ }^{\prime 7}$ while others named it as "Dead space," "Zone of minimal conflict," "Denture space," "Reciprocal zone" and "Zone of neutral muscular function." ",10 The soft tissues which make boundaries of the denture space apply forces that significantly affect the stability of the dentures. ${ }^{2}$ The muscles affecting the NZ are muscles of 
the cheek which include buccinator and masseter, muscles of lips which includes orbicularis oris and caninus and muscles of the tongue. ${ }^{11}$ The main aim of the NZ concept is to identify that area in the oral cavity where the teeth are arranged in such a manner that forces applied by muscles stabilize the denture preferably than dislodge it. ${ }^{3,11}$ However, the NZrecordingmethod has numerous modifications, in terms of functional movements, initial record, impression materials and even recording base design. Different NZ techniques have been described:

- Using only mandibular record base, NZ impression is made using impression compound as an occlusal rim to record the neutral zone contour before final impression ${ }^{8,11-16}$ without inserting maxillary recording base

- After the final impression and calculation of VDO, NZ is recorded using premade specialized denture base and upper wax occlusal rim at the determined $\mathrm{VDO}^{17-23}$

- Recontouring the external surface of the wax-up denture with impression material, , $, 8,11,19,23-26$ or relining the external surface of finished denture by making functional impression ${ }^{22}$

For the recording of NZ authors recommended various materials. These include impression materials-modeling plastic impression compound, $, 8,11,12,14-16,18$ silicone, ${ }^{24}$ soft wax, ${ }^{19,26}$ tissue conditioner, ${ }^{8,22}$ polyvinylsiloxane, ${ }^{20,26}$ and polyether. These materials are beneficial for the clinicians mainly because repeatable and addible properties which facilitate refining the detailed area and lower the viscosity for reproduction of details.

The high viscosity of the material may result in difficulty to geriatric patients as their muscle tone have been reduced and so pushing away the material becomes difficult. With advancing age the tonicity of the muscle reduces, which may also affect the location of the neutral zone. Conversely, the low viscosity material would be technically sensitive as it will be difficult to control the flow of excess material. Rationally, Lynch and Allen recommended slow setting material for the same. ${ }^{23,27}$

On searching the literature, ${ }^{21,23-25,27}$ it was found that various studies have been conducted associated with neutral zone aimed at evaluation of different techniques of recording, a period of edentulousness, the design of record bases, etc, but little concern had been placed for the comparative study of materials used to record neutral zone position.

Taking the above premises into consideration the present study was undertaken to determine the buccolingual location of the NZ in the relation of the center of the alveolar ridge crest and to compare its location recorded by two different material (low fusing impression compound and tissue conditioner) in relation to the crest of the mandibular alveolar ridge. This study would be beneficial as it will help in determining the position of teeth in a zone of minimum conflict so that the stability of the mandibular denture can be attenuated.

\section{MATERIALS AND METHODS}

The subjects with age 50 years and above were selected for the study from the outpatient department after taking ethical clearance and consent of the patients. The location of the NZ to the crest of the ridge was examined in 30 completely edentulous subjects including both males and females. The subjects were selected on the basis of following inclusion criteria- Completely edentulous patients with edentulousness more than 5 years, Absence of any temporomandibular joint disorders, Absence any osseous deformity or disorders. The criteria for exclusion were: any surgery of maxillofacial region, any related surgeries of osseous structures or any abnormality congenital or acquired, patients having ridges with flabby tissues, Subjects exhibiting neuro-muscular disorders or enlargement of orbicularis oris, Subjects with any pathology of tongue, soft or hard tissue pathology, patients in whom teeth got attrited in a very short span of time.

After selection for each subject, the mandibular master cast was prepared in dental stone with base parallel to the residual ridge. A stainless steel wire of 25-gauge was adapted in the form of loops through the crest of the residual ridge on the mandibular cast. This was secured in place with the help of commercial glue. Undercuts were blocked, and denture bases were made in self-polymerizing acrylic resin by sprinkle on technique. The denture base was polymerized in the water bath for 15 minutes at $37^{\circ} \mathrm{C}$. Then it was separated from the cast, and finishing and polishing were done. Following this denture bases were checked in a patient's oral cavity and evaluated for stability, retention, comfort, and extension (Fig. 1).

The mandibular master casts were duplicated twice to fabricate 2 set of record bases, one of them was used as conventional for static recording the jaw relation using wax interocclusal record and mounting on the articulator while the other record bases with the addition of wrought wire loops were used to retain the neutral zone recording materials.

\section{Recording of the Neutral Zone}

The technique I using low fusing impression compound:

- Low fusing impression compound was mixed according to the manufactures instructions and the hot compound was kept on the record base and around the retentive loops, forming a recording rim. 
This record block was used for recording the NZ clinically. The record bases with low fusing impression compound were placed then removed from the water bath and immediately placed inside the mouth, after tempering it. The patients were instructed to perform all the physiologic movements such as sucking, swallowing and producing exaggerated sounds such as 'OOO' and 'EEE' (Fig. 2).

- When the NZ recording was cooled and it becomes hard, it was removed and inspected for any defects and extensions were evaluated. The excess material that was displaced was trimmed off, and if there were any shortage and deficiency, then extra material was mixed and added, and the patient was instructed to repeat all the movements after the denture base is placed on the mandibular ridge. The resulting bulk of the NZ record observed as it demarcates the zone where the artificial teeth can be positioned. The cheeks and lips muscles move inward while the tongue muscles move outward and this synchronized muscle movement mold rim shape to form NZ (Fig. 3A).

\section{Technique II using Tissue Conditioner}

The tissue conditioner was mixed according to the manufactures instruction and placed over the denture

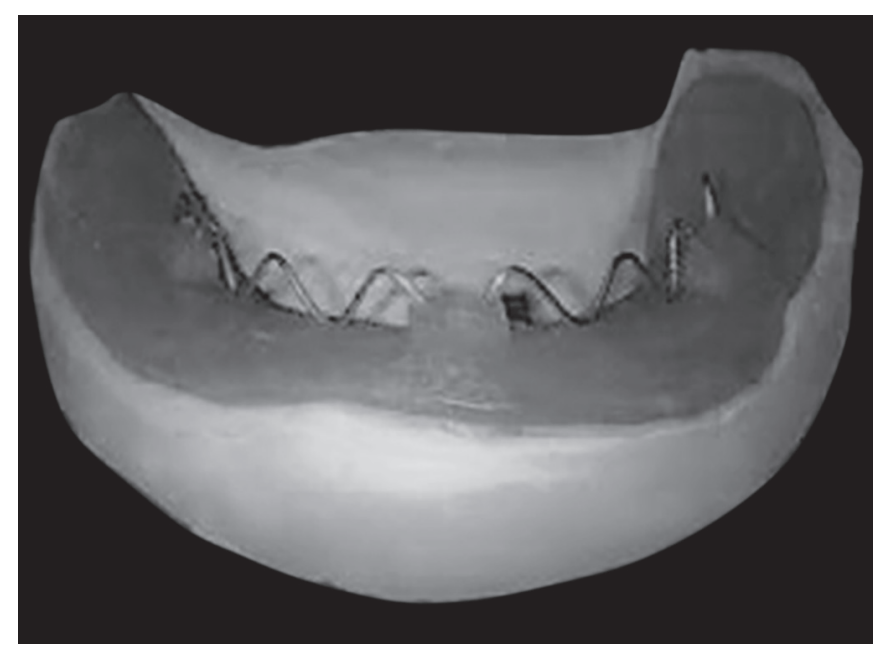

Fig. 1: Adaptation of stainless steel wire on mandibular record base in the form of loops

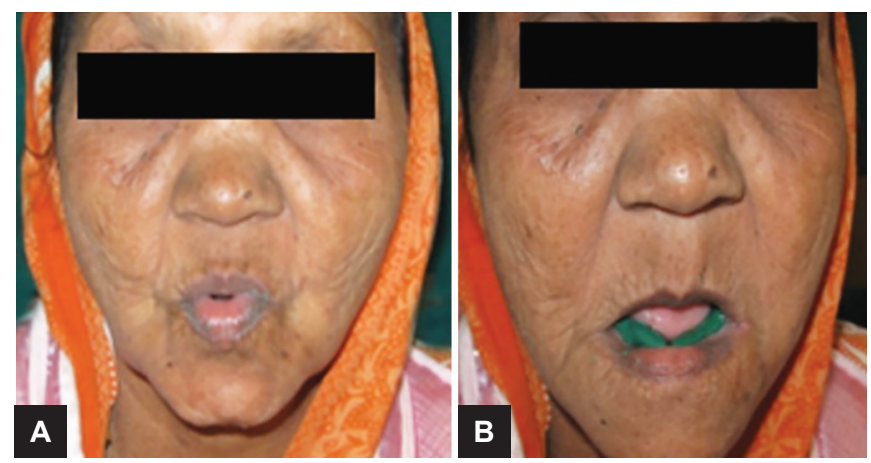

Figs. 2A and B: Recording of the neutral zone by functional movement and "ooo-eee" technique base, and around the retentive loops, precautions were taken not press the lip against the material till it was completely seated. The patient was instructed to perform all movements as done for the first technique, and the neutral zone was recorded in a similar manner. After the setting of material, recording base was taken out of the mouth. It is important that only an adequate amount of material be used for this procedure, as the usage of an excessive amount would force the material forward and above the height of the plane of occlusion (Fig. 3B).

Followed by recording of neutral zone by each technique, again the stability of the denture base was evaluated by instructing the patient to dampen the upper and lower lips with the tongue, open his/her mouth broadly, read the table of 2 and speak words in exaggerated manner such as 'Ohs', 'ahs' and 'ees'. If this movement raised the denture base, it showed that there is less stability may be a result of inadequate and insufficient molding of material. So, the procedure was repeated and tested again till a stable occlusal rim was not achieved.

The mandibular record base with the NZ record was removed from the mouth and an index was prepared for it using a mixture of plasters and pumice. The mandibular cast along with the neutral zone was indexed. The index thus obtained can be used for making of occlusal rims with wax and the placement of teeth. Notches were placed on the mandibular cast for re-orientation of the index. Two notches were placed on either side of the mandibular master cast and three notches at the posterior aspect of the cast. These notches helped in the reorientation of the index on the cast. The mandibular master cast was placed on a tile after the neutral zone record was sealed onto the cast and boxing of this was done using modeling wax with a space of $10-15 \mathrm{~mm}$ all around the cast. Plaster pumice was mixed and poured into it, after applying Vaseline as separating media all over the cast and neutral zone record. After the initial set of the plaster three cuts was made, one on the anterior and two on the posterior aspect at the retromolar area using a saw. Once the final set of the plaster has taken place, these three pieces were
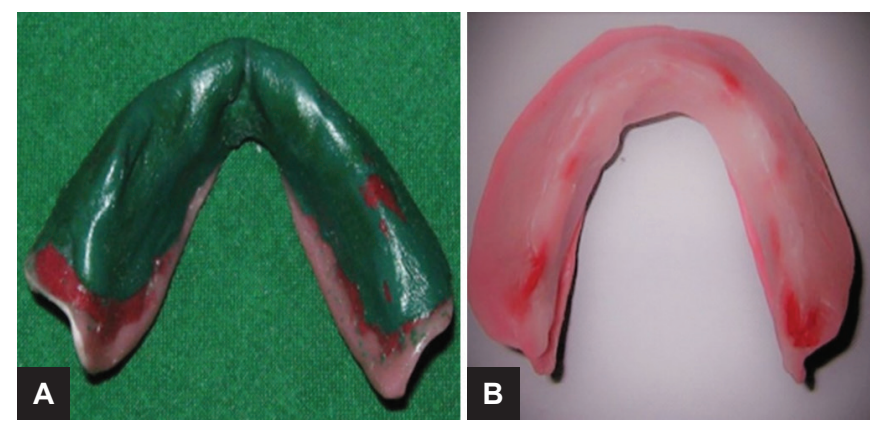

Figs 3A and B: Neutral zone recorded by two materials (A) Low Fusing Impression Compound; (B) Tissue Conditioner 
separated from each other. Following this, the denture base with neutral zone record was removed and another denture base made previously was placed. Then index was reoriented on master cast and on the new record base the mandibular occlusal rim was made by pouring the molten modeling wax in the index. This wax rim thus obtained from the index of each technique, in turn, was used for radiographic assessment of Neutral zone (Fig. 4).

\section{Preparation for radiographic assessment}

A stainless steel wire of 28 and 22-gauge was adapted on the crest of the lower ridge on the cast and also on the center of the entire length of occlusal rim's occlusal surface respectively. Following this, the occlusal radiograph of denture base was made such that the images of the adapted wires were obtained. The distance between the denture base and radiographic machine head was kept 12 $\mathrm{cms}$, and the X-ray central beam was directed at the center of the cast. The following exposure parameters were used 70 kilovolts peak, $8 \mathrm{ma}, 20$ impulses, and 1 sec exposure time. All the radiographic films were developed in a machined automatic processor. Each film was evaluated to determine the relationship between images of these two wires in a buccolingual direction. If both the images of the two wires overlapped, a 0 score was given. The buccal or labial position of NZ wire in relation to the wire representing the center of the ridge in the anterior, premolar and molar region was given a positive value. The location of the NZ wire lingual to alveolar ridge
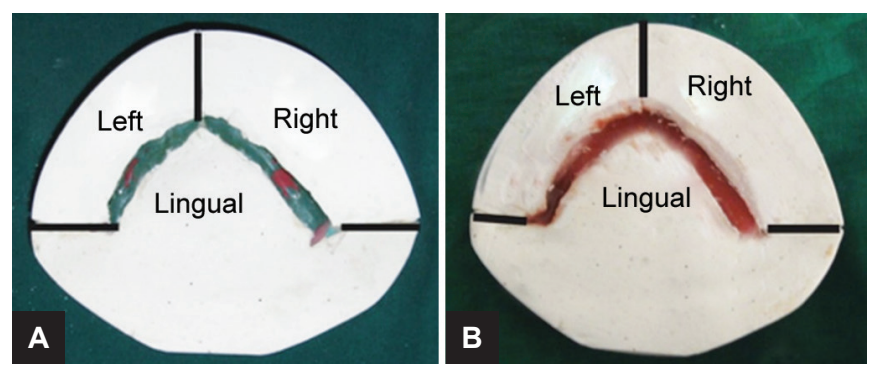

Figs 4A and B: (A) Plaster index for neutral zone record; (B) Plater index poured with baseplate wax crest was given a negative value. All measurements were recorded on the millimeter scale. The location of NZ to alveolar ridge crest was recorded in 5 different locations viz., the anterior, premolar and molar in the left and right region. In this manner, recordings were made for 30 samples (Fig. 5).

The data so obtained were checked for normality, descriptive statistics was done, and comparative analysis was done by the Mann-Whitney U test.

\section{RESULTS}

The data were recorded from 30 patients to analyze the location of NZ in relation to the crest of the ridge recorded by two materials is presented in Table 1 .

Graphical presentation of the location of neutral zone (Graphs 1 to 3) shows that NZ was located lingually in molar region, very close to the crest of the ridge in the pre-molar region and labial in the anterior region both in the right and left side with each of the two material. NZ, when recorded by LFI, extended in the molar region at a range of -3.5 to 3 , Premolar at -1.5 to 1 , an anterior region at -0.5 to 3 on the right side and -2 to 2 and -3.5 to 3 in pre-molar and molar region, respectively on left side. Similarly, when NZ recorded by Tissue conditioner range of extension was -3.5 to 2.5 and -1.5 to 1 in molar and premolar area on the right side respectively. In the anterior it extended from -1 to 2.5 and on left side extension was -1.5 to 2.5 and -3 to 2.5 in premolar and molar region respectively. (Table 1). On Comparative Analysis by Mann-Whitney U Test it was determined that there is no statistically significant difference in the location of the neutral zone in relation to the crest of the ridge recorded by two materials $(p>0.05)$.

\section{DISCUSSION}

The movements of muscles around the denture are highly distinctive and synergistic and complex. The
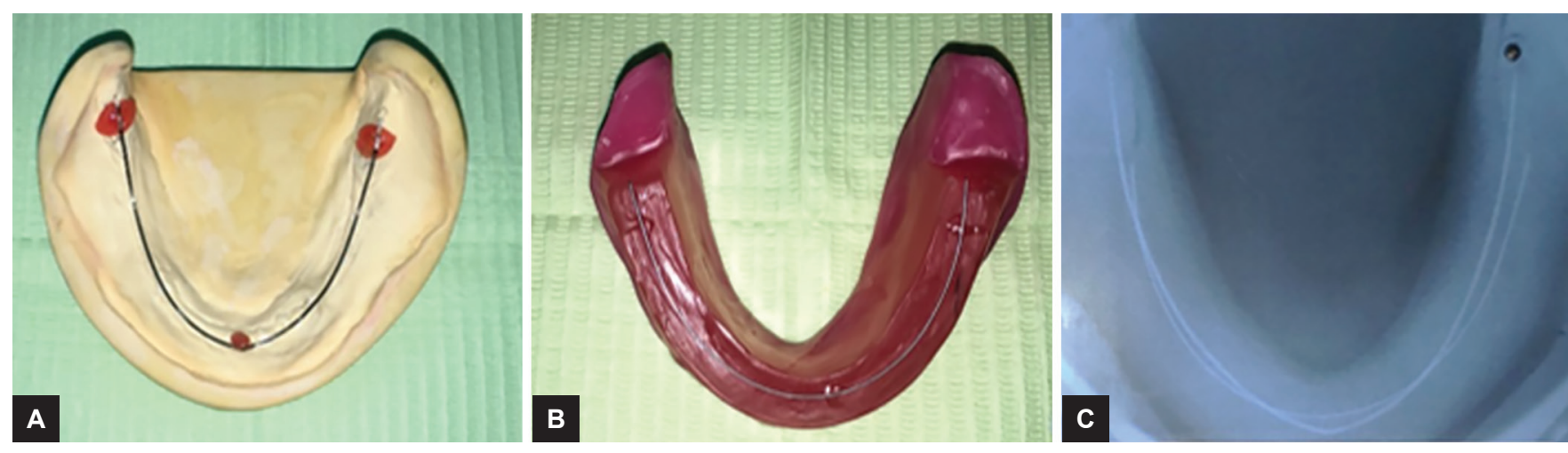

Figs 5A to C: (A) Mandibular cast with 28-gauge stainless steel wire adapted and stabilized over the center of the crest of ridge; (B) Adapted 22-gauge stainless steel wire over the center of occlusal rim achieved obtained from neutral zone record; (C) Occlusal view radiograph to determine bucco-lingual relation between wires. 
Comparison of Neutral Zone Location

Table 1: Descriptive statistics and comparative analysis by Mann Whitney -U Test

\begin{tabular}{|c|c|c|c|c|c|c|c|c|c|c|}
\hline & Groups & $N$ & Mean & $\begin{array}{l}\text { Std. } \\
\text { Deviation }\end{array}$ & Minimum & Maximum & $\begin{array}{l}\text { Mean } \\
\text { Rank }\end{array}$ & $\begin{array}{l}\text { Mann Whitney } \\
U\end{array}$ & $Z$ & $p$ value \\
\hline \multirow[t]{2}{*}{ Molar - Right } & LFI & 40 & 2.18 & 0.91 & -3.5 & 3 & 44.61 & 635.50 & -1.603 & 0.109 \\
\hline & $\mathrm{TC}$ & 40 & 1.81 & 1.00 & -3.5 & 2.5 & 36.39 & & & \\
\hline \multirow[t]{2}{*}{ Premolar - Right } & LFI & 40 & 0.66 & 0.41 & -1.5 & 1 & 42.60 & 716.00 & -0.858 & 0.391 \\
\hline & $\mathrm{TC}$ & 40 & 0.57 & 0.43 & -1.5 & 1 & 38.40 & & & \\
\hline \multirow[t]{2}{*}{ Anterior } & LFI & 40 & 1.55 & 0.89 & -0.5 & 3 & 44.26 & 649.50 & -1.472 & 0.141 \\
\hline & $\mathrm{TC}$ & 40 & 1.30 & 0.71 & -1 & 2.5 & 36.74 & & & \\
\hline \multirow[t]{2}{*}{ Premolar - Left } & LFI & 40 & 0.79 & 0.70 & -2 & 2 & 41.61 & 755.50 & -0.445 & 0.656 \\
\hline & $\mathrm{TC}$ & 40 & 0.74 & 0.74 & -1.5 & 2.5 & 39.39 & & & \\
\hline \multirow[t]{2}{*}{ Molar - Left } & LFI & 40 & 2.06 & 0.77 & -3.5 & 3 & 46.15 & 574.00 & -2.226 & 0.066 \\
\hline & $\mathrm{TC}$ & 40 & 1.66 & 0.81 & -3 & 2.5 & 34.85 & & & \\
\hline
\end{tabular}

LFI - Low fusing impression compound, TC- Tissue conditioners

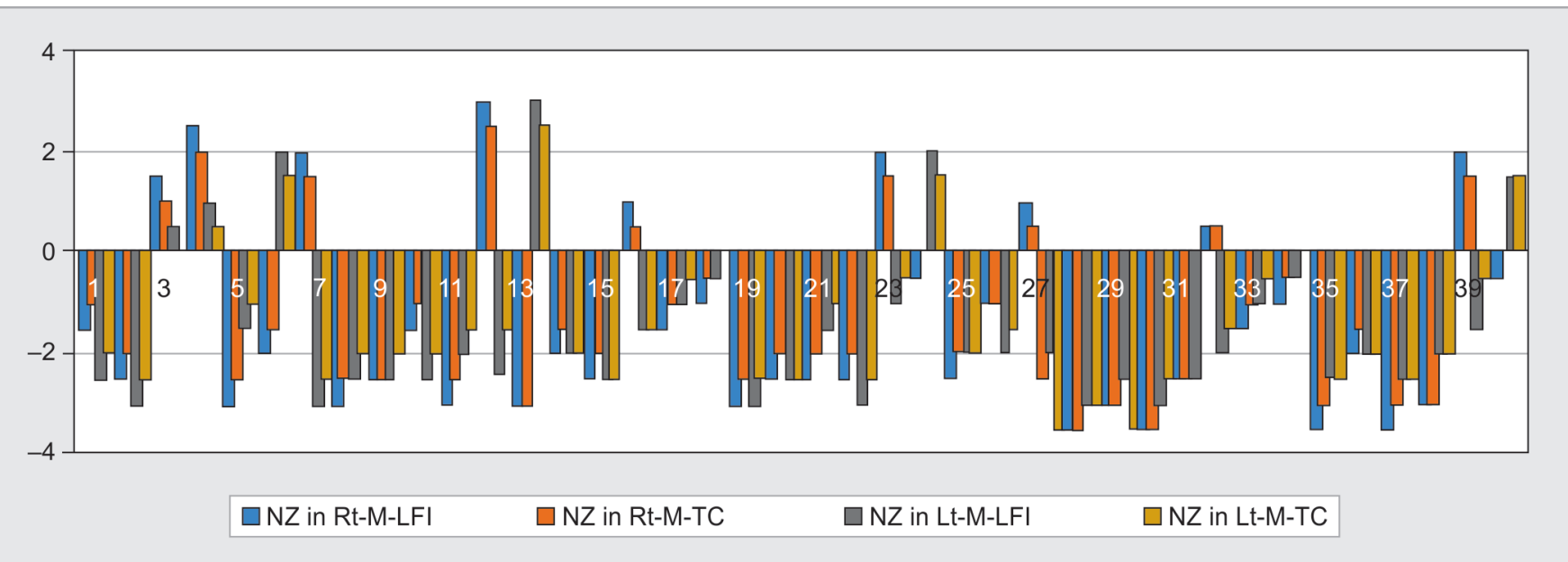

Graph 1: Location of neutral zone in right and left molar region

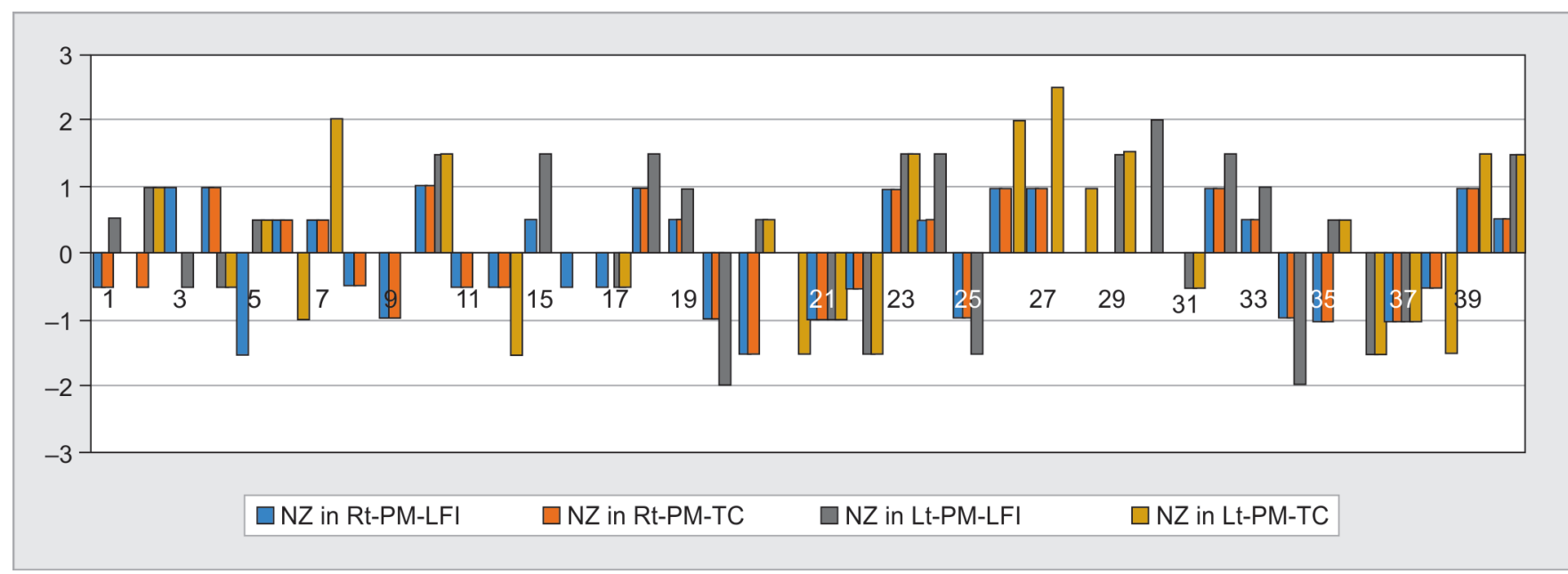

Graph 2: Location of neutral zone in right and left pre-molar region

NZ technique for complete denture fabrication uses the stabilizing potential of muscles and soft tissues, in place of getting dislodged by them. ${ }^{28}$ The NZ records are highly personalized but at the same time reproducible in width, shape, and position. ${ }^{29}$ But, various conditions affect the NZ records, such as functional movements, materials used to record impressions, techniques, muscle tones, vertical dimensions, ${ }^{21}$ the period of edentulism, ${ }^{14}$ uncontrolled transitional tooth extraction. ${ }^{23}$ Since ages, researchers are searching for the ideal position for teeth arrangement in the complete denture. Plentiful Literature is available which advocate the use of NZ for placing the artificial teeth. In spite of its advocated uses still there is lacunae and limited attempts to locate the NZ in relation to the crest of the alveolar ridge. The NZ varied from individual to individual and mainly depends upon muscle tonicity 


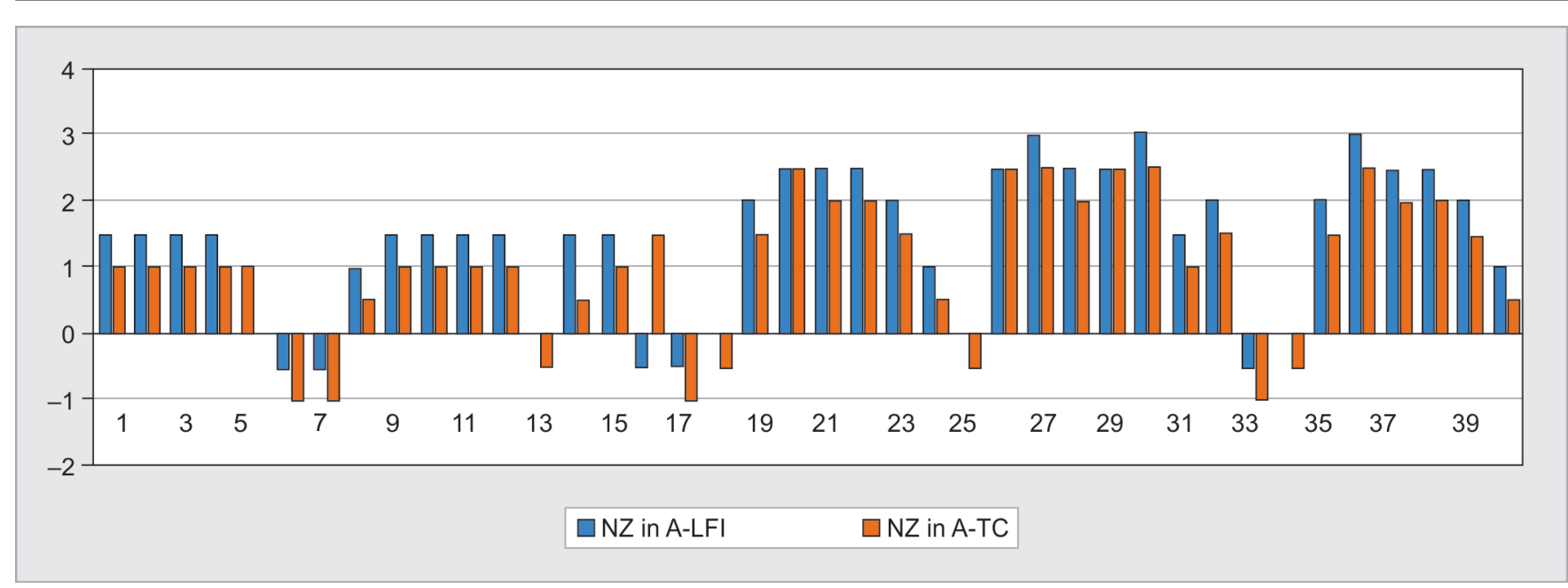

Graph 3: Location of neutral zone in the anterior region

and ridge resorption pattern..$^{8,13,27,28}$ But, along with this it is cited in literature that width and shape of the NZ varies and there could be statistically significant differences when recorded by different materials and methods, ${ }^{29}$ and this may explain why there were differences in the result when the external surface form and the position of the tooth in the finished denture were evaluated in previously reported case. ${ }^{8,24,27}$ Basically, there are two methods of recording neutral zone swallowing neutral zone (SNZ) and phonetic neutral zone (PNZ) techniques, various modifications, and combinations have been suggested but overall concept remains the same. We had used the combination techniques involving swallowing as well as speaking words "ooo" and "eee" thus utilizing the benefits of both techniques. In the present study, two different commonly used material in recording the NZ location in a buccolingual direction in relation to the crest of the ridge was compared by a clinic-radiographic method, remaining all factors were controlled by implementing techniques in a similar manner and in the same patient.

The two commonly available material of clinical use compared in the study were low fusing impression compound and tissue conditioners. The quality of the material to be used in recording neutral zone should be soft, have sufficient working time and easily mouldable by the forces of the tongue and circumoral musculature hence can be used to accurately locate the neutral zone. ${ }^{17,23,27}$ Both the materials used in the present study were the same in these senses but differ in their flow properties. ${ }^{30}$

Low fusing impression compound is a thermoplastic material. It becomes softer on heating and hardens on cooling. This process is reversible. The flow of low fusing impression compound is dependent on its thermoplastic nature. The material itself provides resistance to the forces applied by the surrounding tissues when it is placed in the patient mouth to record neutral zone and as the temperature reduces the amount of this resistance increases. ${ }^{8,20,30}$ Thus, the neutral zone recorded by the technique using low fusing impression compound was mostly away from the crest of the alveolar ridge, as the tongue a strong muscular organ compared to the circumoral muscles like orbicularis oris, initially pushed the material towards labial side in the anterior region while the strong push of the buccinators muscle, in comparison to tongue, shifted the material more towards the lingual side in the molar region. Following this as the temperature of low fusing impression compound in the mouth started reducing, due to its thermoplastic property, there is an increase in resistance, reduction in flow and consequently the material becomes less mouldable to the week forces applied by the musculatures. ${ }^{20}$ So, the neutral zone recorded by this technique would get shifted from its true position.

On the contrary, tissue conditioners are viscoelastic materials. ${ }^{27,30}$ These materials display a various degree of plastic flow for 24-36 hours after mixing. The process by which they change from a fluid mass to a very viscous, flexible, and sponge-like thick solid is based on gelation of the components. Thus these material has long working time, remain flowable for a longer duration of time and also it doesn't resist the forces exerted by the surrounding tissues and have comparatively high flow even after 24 hours. ${ }^{27}$ So, the neutral zone recorded by the technique using tissue conditioners was mostly closer to the crest of the alveolar ridge, because it remained flowable, flexible and mouldable even to the forces of week musculature after a strong push of powerful muscles. Thus, more accurate neutral zone position could be recorded.

The result obtained from this study on patients showed that there is no statistically significant deviation in the location of the neutral zone recorded by low fusing impression compound and tissue conditioners $(p$ value $>0.05)$. In the anterior region, NZ was located labially with a mean of 1.55 and $1.30 \mathrm{~mm}$ by LFI and TC 
(Table 1 and Graph 3). This indicates that NZ was located more labial to the crest of the ridge. Accordingly, the anterior teeth should be positioned more labially to the crest of the ridge. This observation was in association with work of Bhorgonde et al. in 2014. ${ }^{2}$ However, phonetics and esthetics should be considered while setting anterior teeth.

The neutral zone in the molar region in the same patients was between -3.5 to $3 \mathrm{~mm}$ and -3.5 to $2.5 \mathrm{~mm}$ as recorded by LFI and TC respectively (Table 1 and Graph 2). Here the neutral zone was located more lingual to the crest of the ridge for these patients. So the position of the neutral zone is lingual to the crest of the alveolar ridge in the molar region. Consequently, mandibular posterior teeth should be placed towards the lingual side, this is in accordance with Devlin ${ }^{31}$ and Cagna ${ }^{32}$ conclusion. Observations of earlier studies ${ }^{2,32}$ revealed that if the buccolingual width of lower teeth large or if posterior teeth are arranged even $1 \mathrm{~mm}$ lingually, the tongue will lose approximately $1000 \mathrm{~mm}^{3}$ of its functional space. This can lead to an abnormal retracted position of the tongue. Also, during the transformation of the patient from dentulous to completely edentulous phase there is a one-tenth increase in tongue size and this will results in increased pressure on the tongue due to mandibular denture. ${ }^{32}$ These factors should be taken into consideration while the arrangement of posterior teeth during denture fabrication.

The position of the neutral zone in the premolar region was very close to the crest of the ridge, and the range was -2 to 2 for LFI and -1.5 to 2.5 for TC with $p$ value 0.391 and 0.656 on right and left side respectively, and it does not divert towards the labial or lingual side (Table 1 and Graph 2). This may be due to the fact that resorption pattern of the mandible in the premolar region is almost equal from buccal and lingual sides. As a result premolar position does not change considerably compared to the crest of the edentulous ridge. This is in agreement with the conclusions of Besford. ${ }^{33}$ Lott and Levin ${ }^{25}$ stated that when the buccal flange is contoured by the buccinator muscle then its size was much thicker than the size of the regular flange, contours of the dentures developed by NZ technique have proclination in the anterior region and convexities on the buccal surfaces of dentures, especially in the molar zones and in patients with reduced tonicity of facial muscles because of advancing age.

Thus, at the time of teeth arrangement special care should be taken to identify the structural losses and changes due to resorption. It is a well-known fact that as the resorption occurs after loss of natural teeth the maxillary ridge moves lingually and mandibular ridge buccally. The atrophy of mandible is also much greater compared to the maxilla. As a result of this, the denture bearing area in the mandibular ridge decreases buccally and labially. ${ }^{2}$ The NZ technique helps in identifying a zone of minimum conflict for the arrangement of teeth after resorption has taken place. If NZ technique is not followed the teeth arrangement will be purely arbitrary. The standard protocol of teeth arrangement on the crest of the ridge is not in any way true to the original position of natural teeth. In straight words, we should not be rigid in the placement of the teeth over the crest of the ridge or lingual to the crest of the ridge to obtain favorable teeth to ridge relation. On the contrary, teeth should arranged and placed on the basis of buccal and lingual musculature, which is different in each individual.

Complete denture prosthesis constructed using the concept of neutral zone results in a denture, which is in harmony with these lingual and buccal musculatures. The results obtained from this study serves as a guideline for the bucco-lingual placement of artificial teeth in complete dentures by using the minimum and maximum ranges provided in the results. Also, it is ascertained in the study that the location of NZ is not affected by the type of material used in recording it.

\section{Limitations}

Various limitations of the study must be considered. The difference between male and female subjects was not determined, small sample size and cross-sectional design of the study. The effect of muscle strength and tonicity, individually for buccal and lingual side and also the reason for teeth loss was not taken into account. In this study the comparison between impression compound and tissue conditioners was done, other materials like soft wax, a polymer of dimethylsiloxane filled with calcium silicate, silicone, and resilient lining materials have also been suggested for the recording of the neutral zone. Hence, further studies comparing the position of NZ in relation to the crest of the mandibular residual alveolar ridge with different other materials will be helpful.

\section{CONCLUSION}

The present study was carried out to determine the buccolingual relation between the NZ, and the alveolar ridge crest and comparison was made between two commonly used materials low fusing impression compound and tissue conditioners. It was found that the neutral zone was towards the labial side and lingual side in the anterior and posterior region respectively. The position of the neutral zone remains more or less constant in the premolar region with respect to the crest of the residual ridge, in both techniques. Thus, findings of this study may serve as an important guide in the arrangement of teeth for complete denture prosthesis, in the neutral zone and it could be concluded that location of neutral zone is not affected by the material used in recording it. 


\section{REFERENCES}

1. Beressin VE, Schiesser FJ. The neutral zone in complete and partial dentures, 2nd ed. St. Louis, USA:CV Mosby Co.; 1978. p. 73-89.

2. Bhorgonde D., Nandakumar K., Khurana P., et al. An evaluation of the position of the neutral zone in relation to the crest of mandibular alveolar ridge - An In-vivo study. J Int Oral Health. 2014 Apr; 6(2):45-54.

3. Zarb GA, Hobkirk J, Eckert S, Jacob R. Prosthodontic treatment for edentulous patients, 8th ed. St. Louis; CV Mosby Co.; 1975. p. 436-443.

4. Khamis M, Razek A, Abdalla F. Two-dimensional study of the neutral zone at different occlusal vertical heights. J Prosthet Dent 1981;46(5):484-489.

5. Starcke EN Jr. The contours of polished surfaces of complete dentures: A review of the literature. J Am Dent Assoc 1970;81(1):155-160.

6. Russell AF. The reciprocal lower complete denture. J Prosthet Dent 1959;9:180-190.

7. Roberts AL. The effects of outline and form upon denture stability and retention. Dent Clin North Am 1960;4:293-303.

8. Makzoumé JE. Morphologic comparison of two neutral zone impression techniques: A pilot study. J Prosthet Dent 2004;92(6):563-568.

9. Fenn HR, Liddlow KP, Gimson AP. Clinical Dental Prosthetics. 3rd ed. London: Wright; 1994.

10. Beresin VE, Schiesser FJ. The neutral zone in complete dentures 1976. J Prosthet Dent 2006;95(2):93-100.

11. Beressin VE, Schiesser FJ. Neutral zone in complete denture. J Prosthet Dent 1976;36:356-367.

12. Cagna DR, Massad JJ, Schiesser FJ. The neutral zone revisited: from historical concepts to modern application. J Prosthet Dent 2009;101:405-412.

13. Fahmy FM, Kharat DU. A study of the importance of the neutral zone in complete dentures. J Prosthet Dent 1990;64:459-462.

14. Fahmi FM. The position of the neutral zone in relation to the alveolar ridge. J Prosthet Dent 1992;67:805-809.

15. Alfano SG, Leupold RJ. Using the neutral zone to obtain maxillomandibular relationship records for complete denture patients. J Prosthet Dent 2001;85:621e3.

16. Wee AG, Cwynar RB, Cheng AC. Utilization of the neutral zone technique for a maxillofacial patient. J Prosthodont 2000;9:2-7.

17. Gahan MJ, Walmsley AD. The neutral zone impression revisited. Br Dent J 2005;198:269-272.
18. Matthews E. The polished surfaces. Br Dent J 1961;111:407-411.

19. Raybin NH. The polished surface of complete dentures.J Prosthet Dent 1963;13:236e9.

20. McCord JF, Grant AA. Impression making. Br Dent J 2000;188:484-492.

21. Khamis M, Razek A, Abdalla F. Two-dimensional study of the neutral zone at different occlusal vertical heights. J Prosthet Dent 1981;46:484-489.

22. Ohkubo C, Hanatani S, Hosoi T, Mizuno Y. Neutral zone approach for denture fabrication for a partial glossectomy patient: a clinical report. J Prosthet Dent 2000;84:390-393.

23. Lynch CD, Allen PF. Overcoming the unstable mandibular complete denture: the neutral zone impression technique. Dent Update 2006;33:21e2. 24-26.

24. Barrenas L, Odman P. Myodynamic and conventional construction of complete dentures: a comparative study of comfort and function. J Oral Rehabil 1989;16:457-465.

25. Lott F, Levin B. Flange technique: an anatomic and physiologic approach to increased retention, function, comfort, and appearance of dentures. J Prosthet Dent 1966;16:394-413.

26. Wright SM. The polished surface contour: a new approach. Int J Prosthodont 1991;4:159-163.

27. Yi-Lin Yeh, Yu-Hwa Pan, Ya-Yi Chen. Neutral zone approach to denture fabrication for a severe mandibular ridge resorption patient: Systematic review and modern technique. Journal of Dental Sciences 2013;8:432-438.

28. Jitendra J Mete, Santosh Y Dixit, Sumit J Deshpande, Harshad Wagaj, Pravin Gaikwad. A Clinico-radiographic Evaluation of Relation between Neutral Zone and Crest of Mandibular Residual Alveolar Ridge with Different Duration of Edentulousness.J Int Oral Health 2016;8(9):916-921.

29. Karlsson S, Hedegard B. A study of the reproducibility of the functional denture space with a dynamic impression technique.J Prosthet Dent 1979;41:21-25.

30. Anusavice, K.J., Kenneth, J. Phillips' science of dental materials. 11th edition. Elsevier, ; 2003 p. 121-540.

31. Devlin, H. in: Complete dentures: a clinical manual for the general dental practitioner. Springer-Verlag, New York; 2002:55-56.

32. Cagna RD, Massad JJ, Schiesser FJ The neutral zone revisited: From historical concepts to modern application.J Prosthet Dent 2009;101:405-412

33. Besford J. N., Sutton A. F. Aesthetic possibilities in removable prosthodontics. Part 2: start with the face not the teeth when rehearsing lip support and tooth positions. BDJ 2018;224: 141-148. 